\title{
Motivation Affects Self-Efficacy Greater than Age, Sex, and Education in Diabetic Patients in West Coast Area of Java Island
}

\author{
I Wulandari ${ }^{1}$, Kusnanto ${ }^{2}$, S. H. Nufus ${ }^{3}$ \\ ${ }^{1}$ Doctoral Degree Programs, Faculty of Nursing, Universitas Airlangga, Surabaya, Indonesia; ${ }^{2}$ Faculty of \\ Nursing, Universitas Airlangga, Surabaya, Indonesia; Indonesia; ${ }^{3}$ School of Nursing, STIKes Faletehan \\ Serang, Banten, Indonesia
}

\begin{abstract}
Self-efficacy and motivation are required for patient with type 2 diabetes in managing their diabetes. This study used observational analytic design with a cross-sectional approach. Samples recruited were 115 respondents selected by using purposive sampling method. The data analysis used logistic regression with significance level of $\alpha<0.05$. This study results showed that motivation more affects patient's self-efficacy ( $\mathrm{p}$ 0.001) after being controlled by age, sex, and education. Conclusion of this study was that the highest patient motivation is influenced by the patient's desire to recover from his illness and support from the family. The recommendation of this study is how to develop self-efficacy and motivation to establish the adherence of diabetic patients to carry out their self-care management.
\end{abstract}

Keywords: characteristics, motivation, self-efficacy, diabetes mellitus

\section{Introduction}

Diabetes mellitus (DM) is a chronic disease that requires adherence in carrying out self-care in order to achieve glycemic control and slow the emergence of complications. ${ }^{1}$ Patient adherence to do self-care management for current DM is not yet entirely good and optimal. Adherence of DM patients is influenced by internal factors (individual characteristics, knowledge, self-awareness, and motivation) and external factors such as physician's ability and health system support. ${ }^{2}$ The results showed that motivation, self-efficacy, perception, treatment process, and degree of illness can inhibit the implementation of self-care in addition to individual factors such as age and gender. ${ }^{2-4}$ These barriers can affect adherence of DM patients running self-care, causing poor glycemic control, increasing the risk of hypertension, occurrence of complications, and maintenance costs. ${ }^{4}$

\section{Corresponding Author:}

\section{Wulandari}

Doctoral Program, Faculty of Nursing, Universitas Airlangga, Surabaya, Indonesia Email: indah.wulandari-2018@fkp.unair.ac.id
DM patients are expected to increase globally by 204 million, from 425 million in 2017 to 629 million in 2045 or an increase of around $48 \% .{ }^{5}$ Indonesia ranks 6 th out of ten countries with the highest number of patients diagnosed globally with DM, namely 10 million. The highest number of patients diagnosed with DM was at the age of 20-64 years, amounting to 327 million people compared to ages $65-99$ years at 123 million people. ${ }^{5}$

Adherence to self-care management among DM patients requires the confidence of the patient that he can deal with and undergo treatment after being diagnosed. The results of the current research showed that one of the causes of the failure of DM patients to carry out selfcare management is lack of motivation. This motivation is the driver of the patient's self-awareness because of the belief in healing the illness. ${ }^{3,6,7}$ Other factors related to adherence to the implementation of DM self-care are patient characteristics, such as age, gender, occupation, education, and also local culture. , $3,4-12^{4}$

The previous research showed, among other factors, that intrinsic motivation and self-efficacy are often found to be major factors in influencing patients to manage their diabetes. ${ }^{3,9,12-14}$ Motivation makes someone have a strong desire to make efforts so that the goal is achieved. 
Motivation can affect self-efficacy., ${ }^{2,15}$ Self-efficacy of diabetes patients refers to an individual's belief in one's competence in successfully performing a given action on diabetes management. Higher self-efficacy is associated with more prudent self-care behaviors and better glycemic control, indicating that individuals who perceive themselves more confident in managing their disease are also more likely to do so. ${ }^{1,8,15}$

The aim of this study was to determine the selfefficacy determinants of the characteristics and motivation of patients with type 2 diabetes mellitus.

\section{Method}

Study Design, Setting, and Sampling: The study design used observational analytic with cross-sectional design which was held from May to September 2018. The population in this study was diabetes mellitus outpatients. The sampling technique used a nonprobability sampling with purposive sampling approach as many as 115 subjects.

Study Variables: The questionnaires for motivation measurement were validated and the reliability tested with Cronbach's alpha value of 0.92. Motivational instruments were adopted from previous studies and validity and reliability were tested by researchers, consisting of 13 closed-ended questions.

The self-efficacy questionnaire used the Diabetes Management Self-Efficacy Scale (DMSES) in which the language had been modified; the validity and the reliability were tested with Cronbach's alpha 0.919, consisting of 16 questions.

The process of data collection was carried out in an outpatient room. Patients who met the inclusion criteria and were willing to be involved as research subjects were determined as respondents. Respondents involved were given instruments in a certain room so that the confidentiality of the data was guaranteed.

Data Analysis: The data were analyzed using SPSS software version 16 . The data analysis was performed by using Chi square in bivariate and logistic regression for multivariate analysis. The research results are displayed in the form of percentages, $p$ values and OR values

\section{Results}

The results of the analysis in Table 1, show occupation variable has $P$ value 0.442 , so that it is excluded from the model. However, sex and education variables remain included in the model because previous studies show that age and education are related to self-efficacy.

Table 1: Bivariate selection of independent variables and self-efficacy $n=115$

\begin{tabular}{|c|c|c|}
\hline Variables & P Value & OR \\
\hline Age & 0.007 & 2.121 \\
\hline Sex & 0.198 & 1.754 \\
\hline Education & 0.018 & 0.610 \\
\hline Occupation & 0.442 & 1.173 \\
\hline Motivation & 0.001 & 4.239 \\
\hline
\end{tabular}

Table 2 shows the results of the first multivariate analysis of the four dependent variables; the education variable has the highest $p$ value. Table 3 shows that, after occupation variable is excluded, there is no change in OR value $>10 \%$ in other variables. So the occupation is put back into the model. Then, because the education variable has $\mathrm{P}$ value greater than 0.005 , it is excluded from the model.

Table 2: First modeling logistic regression $\mathbf{N}=155$

\begin{tabular}{|c|c|c|c|c|}
\hline Variables & B & P Value & OR & 95\% CI (lower-upper) \\
\hline Age & 0.747 & 0.081 & 2.111 & $0.912-4.882$ \\
\hline Sex & 0.573 & 0.272 & 1.774 & $0.638-4.928$ \\
\hline Education & -0.492 & 0.311 & 0.611 & $0.236-1.582$ \\
\hline Motivation & 1.462 & 0.001 & 4.312 & $1.838-10.120$ \\
\hline
\end{tabular}

Table 3: Changes in OR values before and after occupation variable is excluded $\mathbf{n}=\mathbf{1 5 5}$

\begin{tabular}{|c|c|c|c|}
\hline Variables & OR gold standard & OR without occupation variable & The OR Change \\
\hline Age & 2.121 & 2.111 & $5 \%$ \\
\hline Sex & 1.754 & 1.774 & $1,1 \%$ \\
\hline Education & 0.610 & 0.611 & $0,2 \%$ \\
\hline Occupation & 1.173 & & $1,7 \%$ \\
\hline Motivation & 4.239 & 4.312 & \\
\hline
\end{tabular}


Table 4 shows the results of the second multivariate analysis of the three dependent variables; the sex variable has the highest $p$ value.

Table 4: Second modeling logistic regression $N=155$

\begin{tabular}{|c|c|c|c|c|}
\hline Variables & B & P Value & OR & 95\% CI (lower-upper) \\
\hline Age & 0.847 & 0.041 & 2.334 & $1.034-5.268$ \\
\hline Sex & 0.824 & 0.071 & 2.280 & $0.931-5.584$ \\
\hline Motivation & 1.498 & 0.001 & 4.473 & $1.915-10.449$ \\
\hline
\end{tabular}

Table 5 shows that, after the age variable is excluded, it is found that the education and motivation variables have $\mathrm{OR}>10 \%$, so the age variable is put back into the model. Then, the final analysis is carried out after the age variable is re-entered (Table 10).

Table 5: Changes in OR values before and after age variable is excluded $\mathbf{n}=\mathbf{1 5 5}$

\begin{tabular}{|c|c|c|c|}
\hline Variables & OR gold standard & OR without occupation variable & The OR Change \\
\hline Age & 2.121 & 2.015 & $5 \%$ \\
\hline Sex & 1.754 & & \\
\hline Education & 0.610 & 0.471 & $23 \%$ \\
\hline Motivation & 4.239 & 3.908 & $7.8 \%$ \\
\hline
\end{tabular}

Table 6: Logistic regression modeling results

\begin{tabular}{|c|c|c|c|c|c|}
\hline & B & P value & OR & \multicolumn{2}{|c|}{$\begin{array}{c}\text { 95\% CI } \\
\text { (lower-upper) }\end{array}$} \\
\hline Age & 0.747 & 0.081 & 2.111 & 0.912 & 4.882 \\
\hline Sex & 0.573 & 0.272 & 1.774 & 0.638 & 4.928 \\
\hline Education & -0.492 & 0.311 & 0.611 & 0.236 & 1.582 \\
\hline Motivation & 1.462 & 0.001 & 4.312 & 1.838 & 10.120 \\
\hline
\end{tabular}

The final results of multivariate analysis are shown in Table 6. It shows a significant correlation between motivation and self-efficacy, while the variables of age, education, and gender become the control variables. The results of the analysis showed that the Odd Ratio (OR) of the motivation variable was 4.3 (95\% CI: 1,838 - 10,120), meaning that patients with high diabetes motivation would increase their chances of showing positive self-efficacy by four times compared to those with low motivation after being controlled by age, gender, and education.

\section{Discussion}

The results of this study indicated that motivation plays an important role in the self-efficacy of diabetic patients to carry out self-care. Motivation provides a more meaningful correlation than age, sex, and education. This study revealed that internal motivation is important in shaping the beliefs and confidence in carrying out self-care. Patients with strong motivation have strong fighting strength, so that they are not burdened to undergo diabetes management and this can affect patient self-efficacy. ${ }^{2,15,16}$

Self-efficacy is part of the most important mechanism of human self-reflection and is one part of human agents. Human beliefs about self-efficacy affect the form of the action that they will choose to do, what effort they will give to this activity, how long as they will survive in the face of obstacles and failures, as well as their toughness following a setback. ${ }^{15}$ Self-efficacy has a very strong quality influence in human actions. Self-efficacy combines with the environment, previous behavior, and other personal variables, especially expectations, for results to produce behavior. People who believe that 
they can do something that has the potential to be able to change events in their environment will be more likely to act and be successful than people who have low selfefficacy. ${ }^{1,15}$

The results of this study were supported by several previous studies. Internal motivation and self-efficacy play the biggest role in diabetes management. Therapy, advice from a professional health worker, or existing health facility is not sufficiently helpful if the patient does not have the desire within himself to be willing to comply with the recommended treatment. ${ }^{2,3,9}$ Motivation constraints that are commonly encountered and based on the results of previous research are the boredom of adherence on diet, continuity in exercising, and fear of complications due to prolonged medication. ${ }^{2,6,8,9}$ The concept and assumption of a diet, for example, is a factor that is often found as an obstacle to the implementation of diabetes diet management when there is no motivation to run it. ${ }^{1,9,12}$

Motivation can also affect other diabetes self-care adherence, such as medication failure. Recent study found that $50 \%$ of medication failure was caused by physician factors, $30 \%$ of patient factors, and $20 \%$ healthcare-related factors. ${ }^{17}$ Patient factors that contribute to the failure of treatment for diabetes are denial of the disease, denial of the seriousness of the disease, low health literacy, high cost of medication, too many medications, side effects of the medication, poor communication between physician and patient, lack of trust in physician, depression, lifestyle and absence of symptoms. ${ }^{17,18}$

Motivation is not the only factor that influences self-efficacy. Patient characteristics can also affect the efficacy of his treatment of the disease and the care that must be taken..$^{13,19,20}$ The study also showed that patients over 56 years had more positive self-efficacy than those under the age of 56. The reason obtained from in-depth interviews was that they were more receptive to their illness than those aged less than 56 years. Especially for elderly patients (over 60 years), they lived their lives and diseases by surrendering to God and had no difficulty in carrying out therapy according to the advice of a doctor or nurse, while younger patients said it was more difficult to accept the disease and didn't expect to have diabetes therapy and management every day of their lives., ${ }^{4,8,13}$ Psychologically, acceptance of the disease and surrender to the ultimate God helped the patients sincerely set the therapeutic program. ${ }^{1,7,21}$
The limitation of this study is not analyzing external factors that can affect self-efficacy, such as family factors or health workers. Limitations in sampling also became one of the weaknesses in this study. Samples should be taken randomly so that the results are better and cover a wider area.

\section{Conclusion}

The findings revealed that motivation had a great potential to achieve the self-efficacy needed to achieve glycemic compliance and control. The characteristics of age, education, and gender were confounding factors that can affect self-efficacy, but can be overcome if the internal factors, such as motivation, are more positive. The findings can explain why motivation and selfefficacy are very important for adequate glycemic control. This research can be developed to find internal self-efficacy factors, including internal motivation, to achieve self-care adherence and glycemic control.

Ethical Clearance: The study protocol was approved by The Faculty of Nursing Science of Universitas Islam Agung Semarang Indonesia.

Source of Funding: This research was supported and funded by the institution of Faletehan Serang Banten Institute of Health through the Institute for Research and Community Service.

\section{Conflict of Interest: None}

\section{REFERENCES}

1. Al-Khawaldeh OA, Al-Hassan MA, Froelicher ES. Self-efficacy, self-management, and glycemic control in adults with type 2 diabetes mellitus. J Diabetes Complications [Internet]. 2012;26(1):10-6. Available from: http://dx.doi. org/10.1016/j.jdiacomp.2011.11.002

2. Simon-Tuval T, Shmueli A, Harman-Boehm I. Adherence to Self-Care Behaviors among Patients with Type 2 Diabetes-The Role of Risk Preferences. Value Heal [Internet]. 2016;19(6):844-51. Available from: http://dx.doi. org/10.1016/j.jval.2016.04.003

3. Joo JY, Lee H. Barriers to and facilitators of diabetes self-management with elderly KoreanAmerican immigrants. Int Counc Nurses. 2016;63:277-84. 
4. Mogre V, Abanga ZO, Tzelepis F, Johnson NA, Paul C. Adherence to and factors associated with self-care behaviours in type 2 diabetes patients in Ghana. BMC Endocr Disord. 2017;17(1):1-8.

5. IDF. IDF Diabetes Atlas. International Diabetes Federation. Brussels, Belgium; 2017. 1-150 p.

6. Heissam K, Abuamer Z, El-Dahshan N. Patterns and obstacles to oral antidiabetic medications adherence among type 2 diabetics in Ismailia, Egypt: A cross section study. Pan Afr Med J. 2015;20:1-7.

7. Yang F, Pang JS, Cheng WJY. Self-Care Adherence and Psychological Functioning of Older Patients with Type 2 Diabetes: Effects of Persuasion, Social Pressure, and Self-Efficacy. J Clin Psychol Med Settings. 2016;23(4):389-401.

8. Cosansu G, Erdogan S. Influence of Psychosocial Factors on Self-Care Behaviors and Glycemic Control in Turkish Patients With Type 2 Diabetes Mellitus. J Transcult Nurs. 2014;25(1):51-9.

9. Ahola AJ, Groop PH. Barriers to self-management of diabetes. Diabet Med. 2013;30(4):413-20.

10. Gamboa Moreno E, Mateo-Abad M, Ochoa de Retana García L, Vrotsou K, del Campo Pena E, Sánchez Perez Á, et al. Efficacy of a selfmanagement education programme on patients with type 2 diabetes in primary care: A randomised controlled trial. Prim Care Diabetes. 2018;1-12.

11. Quinn LT, Riley BB, Ruggiero L, Gerber BS, Chavez N, Hernandez R, et al. Correlates of self-care in low-income African American and Latino patients with diabetes. Heal Psychol. 2013;33(7):597-607.

12. Yuan X, Sun W, Luo X, Yang J, Li C, Ge S, et al. Factors Influencing Self-Management in Chinese Adults with Type 2 Diabetes: A Systematic Review and Meta-Analysis. Int J Environ Res Public Health. 2015;12(9):11304-27.
13. Mansyur CL, Rustveld LO, Nash SG, JibajaWeiss ML. Social factors and barriers to selfcare adherence in Hispanic men and women with diabetes. Patient Educ Couns [Internet]. 2015;98(6):805-10. Available from: http://dx.doi. org/10.1016/j.pec.2015.03.001

14. Grant JS, Steadman LA. Barriers to diabetes self-management among rural individuals in the workplace. Work Heal Saf. 2016;64(6):243-8.

15. Bandura A. Self-efficacy in changing societies. Cambridge: Cambridge University Press; 1995.

16. Cuevas HE, Brown SA. Self-Management Decision Making of Cuban Americans With Type 2 Diabetes. J Transcult Nurs. 2018;29(3):222-8.

17. Reach G, Pechtner V, Gentilella R, Corcos A, Ceriello A. Clinical inertia and its impact on treatment intensification in people with type 2 diabetes mellitus. Diabetes Metab [Internet]. 2017;43(6):501-11. Available from: http://dx.doi. org/10.1016/j.diabet.2017.06.003

18. Jannoo Z, Mamode Khan N. Medication Adherence and Diabetes Self-Care Activities among Patients with Type 2 Diabetes Mellitus. Value Heal Reg Issues. 2019;18:30-5.

19. Abubakari A, Cousins R, Thomas C, Sharma D, Naderali EK, Park H, et al. Sociodemographic and Clinical Predictors of Self-Management among People with Poorly Controlled Type 1 and Type 2 Diabetes: The Role of Illness Perceptions and Self-Efficacy. J Diabetes Res. 2016;2016.

20. Chlebowy DO, Myers J, Mendes AN. SocioDemographic Variables and Self-Efficacy in Caucasian and African American Adults with Type 2 Diabetes. South Online J Nurs Reseacrh. 2010;10(December).

21. Kanbara S, Taniguchi H, Sakaue M, Wang DH, Takaki J, Yajima Y, et al. Social support, selfefficacy and psychological stress responses among outpatients with diabetes in Yogyakarta, Indonesia. Diabetes Res Clin Pract. 2008;80(1):56-62. 